\title{
COMPLEMENTARY AND ALTERNATIVE MEDICINE USAGE IN CANCER PATIENTS IN SOUTHEAST OF TURKEY
}

\author{
Mehmet Kucukoner $^{1}$, Zulfikar Bilge ${ }^{2}$, Abdurrahman Isıkdogan ${ }^{1}$, M. Ali Kaplan ${ }^{1}$, Ali Inal ${ }^{1}$, \\ Zuhat Urakci ${ }^{1}$.
}

\author{
${ }^{1}$ Medical Oncology Department, Dicle University Medicine Faculty, Diyarbakir, Turkey \\ ${ }^{2}$ Internal Medicine Department, Dicle University Medicine Faculty, Diyarbakir, Turkey \\ *E- mail:drmehmetonko@hotmail.com
}

\begin{abstract}
The aim of this study was to investigate the frequency of complementary and alternative medicine (CAM) methods and clinical characteristics in cancer patients in southeast of Turkey. A total of 324 patients (173 female) were enrolled to this study. Questionnaire was applied to all patients individually for approximately 15 minutes by a doctor. At least one CAM method was used by $62 \%(n=201)$ of the patients. $82.5 \%(n=166)$ of patients treated with CAM were using at least one herbal species. Likewise, $40.9 \%(68 / 166)$ of these patients were using herbal mixtures and $39.8 \%(66 / 166)$ of them were using single herbal as nettle (Urtica dioica) or its seed, $19.3 \%(32 / 166)$ of them were using other herbals. CAM methods were preferred more frequently by the patients with metastatic stage $(p=0.005)$, receiving palliative treatment $(p<0.001)$, chemotherapy $(\mathrm{p}=0.020)$, in between $40-60$ ages patient groups $(\mathrm{p}=0.002)$, and when duration of disease was lengthened $(\mathrm{p}=0.002)$. CAM use among cancer patients is quite common. Presence of metastatic cancer at diagnosis, receiving chemotherapy and palliative treatment and long disease duration were found as main associated factors for CAM usage.
\end{abstract}

Key words: Complementary and alternative medicine; herbal therapy; cancer.

\section{Introduction}

Complementary and alternative medicine (CAM) is defined as a group of healthcare systems, applications and medical products that are not considered as a part of the conventional medicine (NCCAM, 2010). Definitions of complementary medicine and alternative medicine are different. Complementary medicine describes treatment methods that are used in addition to conventional treatments, while alternative medicine involves treatments that are used instead of standard medical treatments (Catherine, 2011).

For treatment purposes, patients use alternative methods, such as special diets, various herbal mixtures, vitamins, and methods of traditional eastern and western medicine, mind-body interventions. Use of complementary and alternative medicine methods has gradually increased in recent year's worldwide (Ernst, 1998). Use of CAM, estimated as applied by one-third to over $80 \%$ of patients during active cancer treatment, is also seen in the post treatment setting (Goldstein,2008). Studies show that approximately $38 \%$ of adults and $12 \%$ children living in the USA were using at least one of the CAM methods (Catherine, 2011). Complementary therapy is used widely among patients with cancer. When general distress of cancer patients is considered, it may provide potential benefits for patients who seek treatment traditional and complementary (De Lemos, 2005). Studies revealed that a majority of cancer patients, in particular, referred to CAM methods. One study has demonstrated that $83.3 \%$ of patients with cancer used at least one CAM method and $62.6 \%$ of these patients referred to vitamins and herbal products (Mary, 2000). In a study in Turkey, use of CAM was $87 \%$, herbal medicine usage was $62 \%$ (Meryem, 2007).

The key questions regarding the use of CAM methods that should be answered are whether these methods are actually effective and safe and how they interact with chemotherapy agents. Many herbs and some CAM applications may metabolically interact with conventional chemotherapy and may impair the effectiveness of chemotherapy. In addition, some of these herbal therapies may have toxic effects (Topuz, 2007). Although a significant portion of the CAM methods have not been investigated and sufficient amount of evidence on their efficacy is not present, they are still favored by patients (Angell, 1998; Brigden, 1998).

The reasons why a considerable number of patients with cancer choose to seek alternative treatments may include the fact that this is one of the most serious and painful disease compared to other diseases, that chemotherapy has severe adverse effects and that it is perceived by the public as a highly deadly disease and the conventional method of treatment is also has its own limitations (Catherine, 2011). Although the high demand for CAM practices among patients with cancer is related to the nature and severity of the disease, it may also have close links with the individual's belief system and cultural and ethnic background (Topuz, 2007).

The present study has been planned to determine the frequency of CAM uses including the methods which are preferred by cancer patients in Turkey and to reveal the socio-demographic, medical features and the factors which lead the patients to CAM use. 


\section{Materials and Methods}

The study was conducted, on the inpatients and outpatients, who were treated in Dicle University Faculty of Medicine Medical Oncology Department, during October 2009 and March 2010. 324 patients, with median age 48 (16-85) years were enrolled in the present study. Informed consents of patients were taken. The study was conducted in compliance with the "Ethical principles for medical research involving human subjects" of Helsinki Declaration. The data of the study were obtained from the patient files and by administering a questionnaire. The questionnaire, included questions that aim to find out the frequency of CAM use among patients, the most commonly used methods and the reasons that lead patients to use these methods, as well as questions that aim to determine patients' sociodemographic and medical characteristics believed to be associated with CAM use. The questionnaire consisted of 24 questions. Most of them were multiple-choice questions; however, the patients were allowed to add further comments. The questionnaire was structured to recover sociodemographic data (education, marital status, place of residence, profession, CAM methods used etc). The questionnaires were administered during face-to-face meetings with patients and about 15 minutes were allocated for each patient by the doctor in the hospital. Data obtained from the study were analyzed with a computer using SPSS 11.5 (Statistical Package for Social Sciences) software. Chi-square was used for comparisons.

\section{Results}

Patients CAM use and their sociodemographic and medical characteristics were compared. Comparison of patients' gender, marital status, health insurance, place of residence (rural or urban), profession, economical status, and their Data generated during the study are depicted in Tables 1-3 below. Of the 324 patients, $173(53.4 \%)$ were females and 151 (46.6\%) were males. The number of patients who used at least one CAM method was $201(62 \%)$. The most commonly used CAM method was herbal origin. Herbal methods were used by $166(51.2 \%)$ of all patients and by $166(82.5 \%)$ of those using CAM methods. Of the patients using herbal method, 68(40.9\%) used herbal mixtures and 66(39.8\%) were using single herbal as nettle (Urtica dioica) or seeds; 32(19.3\%) were using other herbals (such as green tea, oregano). Of the CAM users, $27.3 \%$ $(n=55)$ represented the patient group receiving dietary supplements like honey or grape molasses and was the second in frequency (Table 3).

Table 1: The relation between socio-demographic characteristics and use of CAM

\begin{tabular}{|c|c|c|c|c|}
\hline & Yes & No & Total & P Value \\
\hline & n (\%) & n (\%) & n (\%) & \\
\hline \multicolumn{5}{|l|}{ Age, years } \\
\hline $16-29$ & $24(11.9)$ & $16(13)$ & $40(12.3)$ & \\
\hline $30-39$ & $34(16.9)$ & $19(15.4)$ & $53(16.4)$ & \\
\hline $40-49$ & $55(27.4)$ & $27(22)$ & $82(25.3)$ & 0.002 \\
\hline $50-59$ & $51(25.4)$ & $16(13)$ & $67(20.7)$ & \\
\hline $60 \geq$ & $37(18.4)$ & $45(36.6)$ & $82(25.3)$ & \\
\hline \multicolumn{5}{|l|}{ Stage } \\
\hline Early stage cancer & $95(47.3)$ & $78(63.4)$ & $173(53.3)$ & 0.005 \\
\hline Metastatic stage & $106(52.7)$ & $45(36.6)$ & $151(46.7)$ & \\
\hline \multicolumn{5}{|l|}{ Treatment } \\
\hline Curative & $71(35.3)$ & $79(64.2)$ & $150(46.3)$ & 0.001 \\
\hline Palliative & $130(64.7)$ & $44(35.8)$ & $174(53.7)$ & \\
\hline \multicolumn{5}{|c|}{ Duration of the disease } \\
\hline Less than 1 years & $58(28.9)$ & $54(43.9)$ & $112(34.5)$ & \\
\hline $2-3$ years & $75(37.3)$ & $47(38.2)$ & $122(37.7)$ & 0.002 \\
\hline More than 3 years & $68(33.8)$ & $22(17.9)$ & $90(27.8)$ & \\
\hline \multicolumn{5}{|l|}{ Chemotherapy } \\
\hline Yes & $194(96.5)$ & $110(89.4)$ & $304(93.8)$ & 0.010 \\
\hline No & $7(3.5)$ & $13(10.6)$ & $20(6.2)$ & \\
\hline Total & 201 & 123 & 324 & \\
\hline
\end{tabular}


Table 2: The relation between socio-demographic characteristics and use of CAM

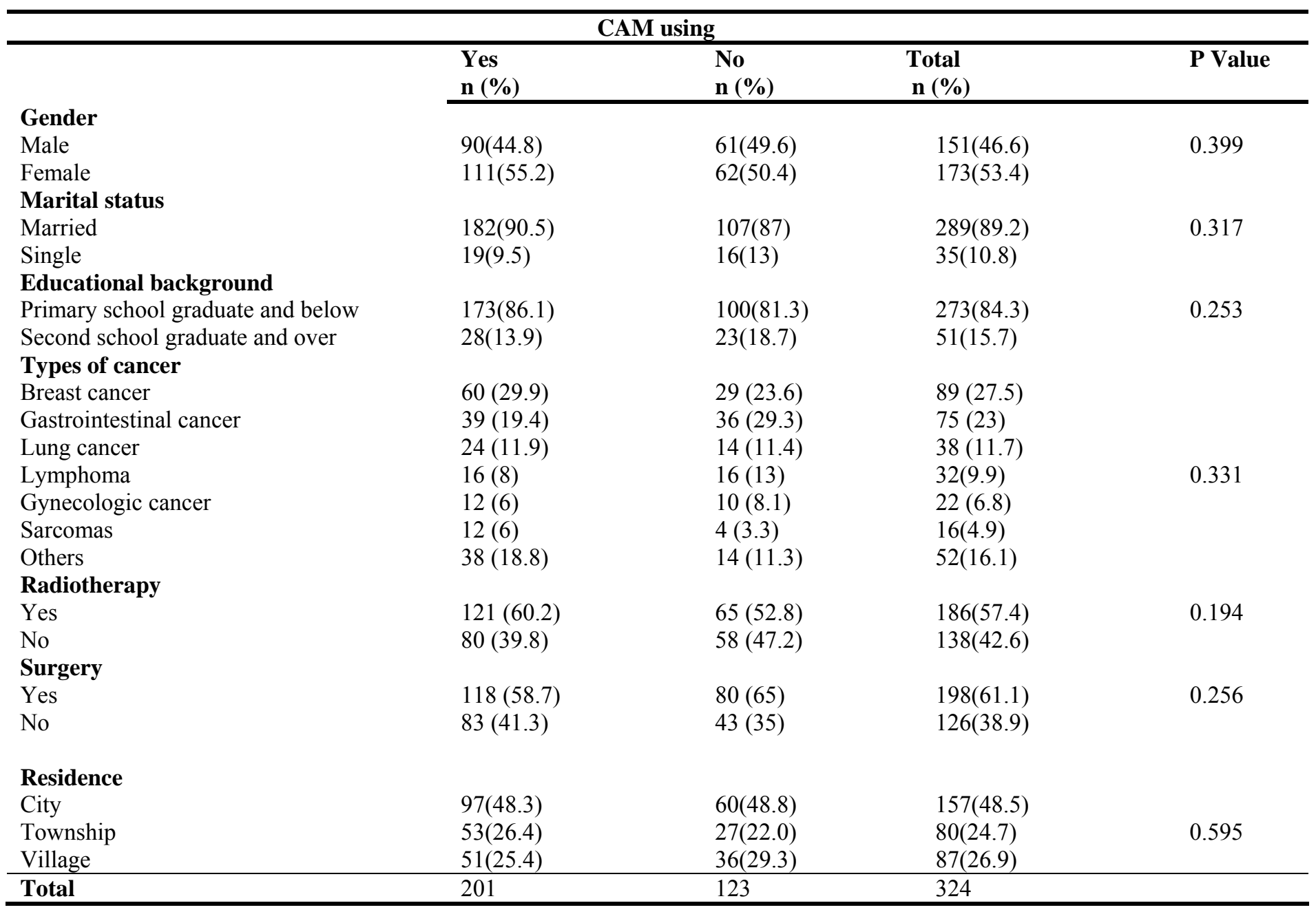

CAM use was no statistically significant different. The relationship between patients' CAM use and their medical status was investigated. There were no significant differences in medical characteristics of the patients who used or not-used CAM (i.e. types of cancer) (Tables 1 and 2).

There was borderline significance $(\mathrm{p}=0.098)$ between age and CAM use but there was statistically significance when the patients grouping in term of age $(\mathrm{p}=0.002)$. Patients above 60 years frequenlty used CAM than younger patients $(\mathrm{p}<0.001)$.

A comparison was made with regard to whether the patients received curative or palliative chemotherapy and CAM use and a significant difference was noted $(\mathrm{p}<0.001)$. Patients receiving curative treatment preferred CAM methods less and those receiving palliative treatment favored these treatments more often.

The relation between the duration of the disease and CAM use was evaluated. Use of CAM methods was more frequent at the longer duration of disease $(\mathrm{p}=0.002)$. CAM use was more frequent in patients who were receiving chemotherapy compared to those who were not, with a statistically significant level $(\mathrm{p}=0.020)$, however receiving radiotherapy or undergoing cancer surgery were not significantly related to CAM usage.

Herbal methods together with chemotherapeutic agents were used by $30.8 \%(n=100)$ of study population and $49.7 \%(n=100)$ of CAM users. Of the patients using herbal methods, $97.6 \%(n=162)$ took these plants orally while the remaining $2.4 \%(n=4)$ used topically. These plants were obtained by $77.7 \%$ of the patients from the city they resided while $21.1 \%$ obtained from another city and $1.2 \%$ from outside the country.

When the reasons of CAM method using were analyzed, $47.3 \%(n=95)$ of the patients answered that they were using these methods for eliminating the disease, not for healing their complaints. In other words, they were using these methods because they were diagnosed with cancer. On the other hand, $17.5 \%(\mathrm{n}=35)$ of the patients were using these methods to treat a complaint such as pain or fatigue. Most of the patients used CAM methods due to recommendation of their relatives or friends (Table 3 ).

When the benefits of the herbal medicine use were examined, $37.9 \%(n=63)$ answered that they benefited, $42.8 \%$ $(\mathrm{n}=71)$ told that they did not benefit and $19.3 \%(\mathrm{n}=32)$ answered that they did not know. On the other hand, to the question if 
http://dx.doi.org/10.4314/ajtcam.v10i1.4

the herbal medicines caused any harm, $6.7 \%$ of the patients answered yes, and $93.3 \%$ of them answered no.

Table 3: Characteristics of patients using CAM method

\begin{tabular}{|c|c|}
\hline Which methods you use CAM? & n (\%) \\
\hline Herbal methods & $166(82.5)$ \\
\hline Dietary supplements (honey, pollen etc) & $25(12.5)$ \\
\hline Religious practices & $6(3)$ \\
\hline Others & $4(2)$ \\
\hline \multicolumn{2}{|l|}{ Why have used CAM method? } \\
\hline For my complaints (pain, fatigue, etc.) & $35(17.5)$ \\
\hline Not to believe in chemotherapy & $4(1.9)$ \\
\hline For supporting to the chemotherapy and decreasing side effects & $25(12.4)$ \\
\hline For my belief on benefit from herbal treatment & $30(14.9)$ \\
\hline To increase body immunity & $12(6)$ \\
\hline Because of my disease ( without complaint) & $95(47.3)$ \\
\hline \multicolumn{2}{|l|}{ Where did you learn the using CAM? } \\
\hline Media tools such as TV-Newspaper & $22(10.9)$ \\
\hline Relatives, friends, relatives such as the proposed & $101(50.4)$ \\
\hline Another patient & $33(16.5)$ \\
\hline Herbalists & $20(9.9)$ \\
\hline Others & $25(12.3)$ \\
\hline
\end{tabular}

\section{Discussion}

Concern about CAM applications is gradually increasing in the world and in Turkey. This interest is particularly pronounced in cancer patients. NCCAM and National Center for Health Statistics published the data on CAM use among Americans in December 2008. According to these data, 38\% of the adults and $12 \%$ of the children in the USA has referred to CAM methods (Catherine, 2011). Many also took herbal preparations (49.3\%), often using more than one remedy (62\%).

Another study by Molassiotis et al. on the use of CAM methods by cancer patients in 14 European countries, which also included Turkey, reported this range as 14.8 to $73.1 \%$, with an average of $35.9 \%$ (Molassiotis, 2005). Use of CAM methods is common not only in western but also in eastern cultures. A study in Japan, on a group of cancer patients, including 3100 subjects identified a CAM use of 45\% (Hyodo, 2005). A study in China on a group of patients with breast cancer showed that nearly all of the patients $(98 \%)$ used alternative methods of treatment after their diagnoses were established (Cui, 2004).

Similar studies have also been conducted in our country: A study by Tas et al. on 615 patients with cancer in 2001, prevalence of CAM use was $47.3 \%$ and $95 \%$ of these patients' preferred herbal remedies, stinging nettle being the most frequently preferred herb (Tas, 2005). In a literature review by Kav et al. in 2008, a total of 5252 patients' data were recovered by reviewing seven studies presented in national congress handbooks and 14 research articles between 2001 and 2007. In this study, the frequency of CAM use ranged between $22.1 \%$ and $84.1 \%$ and the most common method was the herbal mixtures, stinging nettle being the most frequently herb (Kav, 2008). In a study from Turkey's southeastern region, $55.4 \%$ of cancer patients used complementary treatment (Ucan, 2008).

In the present study, the number of patients using at least one CAM method was 201 and the prevalence was $62 \%$. This percentage is consistent with the rates reported from studies from both Turkey and other countries worldwide (Ozlem, 2008; Astin, 1998). The most used method of CAM observed in the present study was herbal remedies. These were used by $51.2 \%$ of all patients and by $82.5 \%$ of those using CAM methods. 
Many studies have sought the relationship between the use of CAM and sociodemographic characteristics of patients. The information in the literature is inconsistent. According to year 2008 December data of NCCAM and National Center for Health Statistics, CAM use is more common among individuals with higher levels of education, females and those with higher levels of income (Catherine, 2011). The study by Molassiotis et al. showed that CAM methods were more frequently used by the young, females and those with higher levels of education (Molassiotis, 2005). In a study in Saudi Arabia, the people used CAM with lower level education (Meryem, 2007). Studies in Turkey shows higher use of CAM among subjects with lower levels of education (Ceylan, 2002).

Comparison of patients' educational status and CAM use also demonstrated a difference. Participants with a high school degree used CAM methods less. Whereas the studies in developed countries, the studies show that the use of CAM is higher among the patients with lower levels of education. Therefore it can be said that CAM methods are used as an alternative treatment to the medical treatment in Turkey contrary to western countries where CAM methods are used as a complementary treatment to the medical treatment by the patients.

The relationship between CAM use and the diagnosis (or cancer localization) and stage of the disease and the received treatments has been investigated in several studies. The study by Kav et al. showed that the duration and stage of the disease and cancer localization were related with CAM use (Kav, 2008). Relationship between patients' medical status and CAM use was also investigated in present study. There were no statistically significant differences between the diagnosis groups (or cancer localization) and rate of applying for CAM. In the present study, significant relationship was found between the stage at the time of diagnosis and the rate of CAM applications. Early-stage cancer patients applied less frequently and advanced-stage cancer patients applied more frequently to CAM applications. A significant relationship between curative or palliative treatment and CAM use was found, so that patients receiving curative treatment used CAM methods less and those receiving palliative treatment preferred these treatments more frequently (Arslan, 2007). The present study confirms that the patients, particularly in the advanced stage of the disease, may feel hopeless because of the failure of the present conventional method of cancer treatment and resort to CAM applications more frequently. Given that most of these patients use herbal remedies together with chemotherapy, it is not certain whether positive effects are associated with herbal medicines, or the chemotherapy itself. Thus an important part of chemotherapy toxicities may be associated with the herbal remedies the patients use based on our observations.

In conclusion, CAM usage among cancer patients is rather common. The most commonly preferred CAM are herbal methods and a great number of the patients use CAM in combination with chemotherapy.

\section{References}

1. National Center for Complementary and Alternative Medicine (NCCAM). what is complementary and alternative medicine? NCCAM Publication D347 2010. World Wide Web URL: http://nccam.nih.gov/health/whatiscam/.

2. Catherine Ulbricht, Lorenzo Cohen, Richard Lee. (2011). Complementary, Alternative, and Integrative Therapies in Cancer care. Devita V, Lawrence T, and Rosenberg S, eds. Cancer Principles \&Practise of Oncology. 9th edition. Philadelphia: Lippincott Williams \&Wilkins; 2550-61.

3. Ernst E, Cassileth BR. (1998). The prevalence of complementary/alternative medicine in cancer: a systematic review. Cancer. 83(4);777.

4. Goldstein MS, Lee JH, Ballard- Barbash R, Brown ER. (2008). The use and perceived benefit of complementary and alternative medicine among Californians with cancer. Psychooncology. 17(1); 19-25.

5. De Lemos ML. (2005). Pharmacist's role in meeting the psychosocial needs of cancer patients using complementary therapy. Psychooncology. 14(3); 204-10.

6. Mary Ann Richardson, Tina Sanders, J. Lynn Palmer, Anthony Greisinger, S. Eva Singletary. (2000). Complementary/alternative medicine use in a comprehensive cancer center and the implications for oncology. Journal of Clinical Oncology. 18(13); 2505-14.

7. Meryem Yavuz, Arzu Ozcan Ilce, Senay Kaymakc1, Gülsen Bildik, Alev Diramali. (2007.) Examination of the complementary and alternative treatment use with breast cancer patients. Turkiye Klinikleri J Med Sci. 27(5);680-86.

8. Topuz E. Complementary and alternative medicine. Tuncer M, editör. (2007) Türkiye' de Kanser Kontrolü. Bakanlık yayın no: 707. Ankara;418-20.

9. Angell M, Kassirer JP. (1998). Alternative medicine-The risks of untested and unregulated remedies (editorial). N Engl J Med. 339(12); 839-41.

10. Brigden ML. (1998) Unproven cancer therapies: A multi-headed hydra. Ann Roy Coll Physicians Surg Can. 31; 9-14.

11. Molassiotis A, Fernadez - Ortega P, Pud D, et al. (2005). Use of complementary and alternative medicine in cancer patients: A Europan survey. Ann Oncol. 16(4);655-63.

12. Hyodo I, Amano N, Eguchi K et al. (2005) Nationwide survey on complementary and alternative medicine in cancer patients in Japan. J. Clin Oncol. 23(12): 2645-54.

13. Cui Y, Shu XO, Gao Y et al. (2004) Use of complementary and alternative medicine by Chinese women with breast cancer. Breast Cancer Res Treat. 85(3); 263-270.

14. Tas F, Üstüner Z,Can G, et al. (2005). The prevalance and determinants of the use of complementary and alternative medicine in adult Turkish cancer patients. Acta Oncologica. 44(2); 161-7.

15. Kav S, Hanoglu Z, Algier L. (2008) Cancer patients in Turkey, the use of complementary and alternative treatment methods: literature review. International Journal of Hematology-Oncology. 18(1); 32-8.

16. Ucan O, Pehlivan S, Ovayolu N, Sevinc A, Camci C. (2008). The use of complementary therapies in cancer patients: a questionnairebased descriptive survey from southeastern Turkey. Am J Clin Oncol. 31(6);589-94.

17. Ozlem Ucan, Seda Pehlivan, Nimet Ovayolu, Alper Sevinc, Celalettin Camci. (2008). The Use of Complementary Therapies in Cancer Patients A Questionnaire-Based Descriptive Survey From Southeastern Turkey. Am J Clin Oncol. 31: 589-594.

18. Astin JA. Why patients use alternative medicine: results of a national study. (1998). JAMA. 279(19):1548.

19. Ceylan S, Hamzaoglu O, Komurcu S and et al. (2002) Survey of the use of complementary and alternative medicine among Turkish cancer patients. Complement Ther Med. 10(2); 94-9.

20. Arslan SA, Misirloglu HC, Cengiz HH and et al. (2007). Questionnaires results of the use of alternative methods in patients receiving radiation therapy. XVII. Ulusal Kanser Kongresi Bildiri Kitabi, Antalya 19-23;190-191. 